\title{
KEMAMPUAN MEDIA FILTER ION EXCHANGE DALAM MENURUNKAN KADAR NITRAT AIR SUMUR GALI DI DAERAH KAWASAN PESISIR Ain Khaer ${ }^{1}$ dan Budirman ${ }^{2}$ \\ 1.2. Poltekkes Kemenkes Makassar, Jurusan Kesehatan Lingkungan ainkhaer2@poltekkes-mks.ac.id
}

\begin{abstract}
Nitrogen compounds in small amounts do not cause interference, on the contrary in high levels can cause pain and even death. It also can cause methemoglobinemia in infants through nitrate-containing foods, especially waterdug wells that have not met the requirements. Filtration technology with ion exchange media to reduce the nitrogen content contained in community dug well water This study aims to determine the ability of ion exchange filtering to reduce levels of nitrate $\left(\mathrm{No}^{3}\right)$ in dug well water in coastal areas. This research is a pre-experiment with a pretest-posttest design that starts with a literature study, preliminary studies and core research, namely the manufacture of filtration equipment with zeolite filter media as ion exchange. Data from laboratory examination results are analyzed descriptively which are explained in the form of tables, graphs, and narratives that illustrate the overall process that occurs during the study. Based on the results of research that the ion exchange filter media can reduce the average level of nitrate (No3-) dug well water from an initial level of $16.43 \mathrm{mg} / \mathrm{I}$ to $5.67 \mathrm{mg} / \mathrm{I}$ with a decrease in efficiency of $10.77 \mathrm{mg} / \mathrm{I}$ (65, $52 \%$ ). The results of this processing have met the standard requirements according to Minister of Health Regulation No. 416 of 1990 concerning clean water that the levels of nitrate (No3-) as the maximum nitrogen in the allowable clean water were $10 \mathrm{mg} / \mathrm{L}$ respectively.
\end{abstract}

Keywords: Filtering, ion exchange, zeolite, activated carbon, nitrate (No3-).

\section{ABSTRAK}

Senyawa nitrogen dalam jumlah yang kecil tidak menimbulkan gangguan, sebaliknya dalam kadar yang tinggi dapat menyebabkan kesakitan bahkan kematian. Selain itu juga dapat menyebabkan methoemoglobinaemia pada bayi melalui makanan yang mengandung nitrat terutama bersumber air sumur gali yang belum memenuhin syarat. Teknologi filterasi dengan media penukar ion untuk mengurangi kandungan nitrogen yang terdapat dalam air sumur gali masyarakat Penelitian ini bertujuan untuk mengetahui kemampuan filterasi ion exchange dalam menurunkan kadar nitrat $\left(\mathrm{No}^{3}\right)$ pada air sumur gali kawasan pesisir. Penelitian ini merupakan Praeksprimen dengan rancangan PretestPostest Design yakni dimulai dengan kajian literatur, studi pendahuluan dan penelitian inti yaitu pembuatan alat filtrasi dengan media filter zeolit sebagai penukar ion. Data hasil pemeriksaan laboratorium dianalisa secara deskriptif yang dijelaskan dalam bentuk tabel, grafik dan narasi yang menggambarkan secara menyeluruh proses yang terjadi selama penelitian. Berdasarkan hasil penelitian bahwa media filter ion exchange mampu menurunkan kadar rata-rata nitrat(No3-) air sumur gali dari kadar awal $16,43 \mathrm{mg} / \mathrm{l}$ menjadi 5,67 mg/l dengan efesiensi penurunan sebesar 10,77 $\mathrm{mg} / \mathrm{l}(65,52 \%)$. Hasil pengolahan ini telah memenuhi persyaratan standar sesuai Peraturan Menteri Kesehatan No. 416 Tahun 1990 tentang air bersih bahwa kadar nitrat (No3-) sebagai nitrogen maksimum dalam air bersih yang diperbolehkan adalah masing-masing $10 \mathrm{mg} / \mathrm{L}$.

Kata Kunci : Filterasi, ion exchange, zeolit, karbon aktif, nitrat $\left(\mathrm{No}^{3-}\right)$.

\section{Pendahuluan}

Air bersih merupakan kebutuhan dasar manusia yang berdampak langsung kepada kesejahteraan fisik, sosial dan ekonomi masyarakat.Untuk saat ini sebagian daerah yang belum terjangkau oleh pelayanan air bersih, khususnya di daerah pedesaan nelayan, masih dilakukan oleh masyarakat itu sendiri. Dengan adanya pertumbuhan penduduk yang pesat dan perkembangan wilayah, maka diperlukan upaya percepatan pembangunan prasarana dan sarana air bersih untuk meningkatkan tingkat pelayanan yang saat ini masih rendah.

Kawasan pesisir merupakan wilayah yang sangat potensial untuk dikembangkan mulai dari sektor perikanan, usaha kecil dan menengah mulai dari industri rumah tangga yang berupa makanan dan makanan ternak, jaring ikan dan bahkan perkapalan, bidang jasa, trasportasi bahkan pariwisata. Melihat adanya potensi ekonomi yang begitu besar maka wilayah pesisir sangat diharapkan menjadi wilayah penyangga bagi pusat-pusat kegiatan. Untuk itu dukungan pada fasilitas umum mulai dari listrik, transportasi jalan darat dan sungai dan laut, telekomunikasi, perumahan, kesehatan dan yang juga sangat penting adalah sarana air bersih.

Pencemaran air sumur oleh aktivitas manusia memberi dampak cemaran pada beberapa paremeter dinataranya cemaran oleh oleh bahan bahan organik menyebabkan kadar amonia dan hidrogen sulfida meningkat. Amonia larut di dalam air dan membentuk senyawa amonium yang cenderung akan mengikat oksigen. Dengan adanya mikroba Nitrosomonas senyawa amonium dan oksigen dapat membentuk senyawa nitrit $\mathrm{NO}^{-2}$ dan dengan adanya mikroba Nitrobakter dapat membentuk senyawa Nitrat $\left(\mathrm{NO}^{3-}\right)\left(\mathrm{NO}^{-3}\right)$. 
Jurnal Sulolipu : Media Komunikasi Sivitas Akademika dan Masyarakat

Vol. 19 No. 12019

e-issn : 2622-6960, p-issn : 0854-624X

Keberadaan Siklus Nitrat $\left(\mathrm{NO}^{3-}\right)$ pada sumur gali yang digunakan oleh masyarakat dikawasan pesisir diawali dengan masuknya nitrogen dan amonia dari buangan domestik dan industri ke dalam badan air. Nitrogen organik mengalami reaksi hidrolisis menghasilkan amonia yang merupakan sumber makanan bakteri nitrogen. Proses oksidasi kemudian terjadi oleh bakteri Nitrosomonas, mengubah amonia menjadi nitrit dan selanjutnya bakteri Nitrobacter mengoksidasi nitrit menjadi Nitrat $\left(\mathrm{NO}^{3-}\right)$.

Setelah nitrit terbentuk, selanjutnya dioksidasi menjadi Nitrat $\left(\mathrm{NO}^{3-}\right)$ oleh bakteri jenis Nitrobacter, hal ini lazim disebut sebagai proses nitrifikasi. Selanjutnya dalam keadaan konsentrasi oksigen terlarut yang rendah terjadi reduksi Nitrat $\left(\mathrm{NO}^{3-}\right)$ menjadi nitrit diikuti lebih lanjut reduksi nitrit menjadi amonia dan gas nitrogen.

Reaksi -reaksi tersebut menyediakan oksigen untuk mikroorganisme yang digunakan dalam keseimbangan materi organik tanpa mengganggu oksigen terlarut yang ada. Dalam keadaan benar-benar anaerob reaksi nitrifikasi tidak dapat berlangsung. Hal tersebut membuktikan bahwa reduksi Nitrat $\left(\mathrm{NO}^{3-}\right)$ dapat meningkat dalam kondisi oksigen terlarut yang rendah (0 hingga $2 \mathrm{mg} / \mathrm{l}$ ). (Aswadi, 2006). Pengaruh nitrit pada kesehatan manusia yaitu, dapat menyebabkan methamoglobinemia dan efek racun kandungan nitrit dalam air lebih besar dari 0 (nol) mg/l. (Soeparman, 2001)

Nitrat $\left(\mathrm{NO}^{3-}\right)$ dan nitrit $\left(\mathrm{NO}^{2-}\right)$ adalah ion-ion anorganik alami, yang merupakan bagian dari siklus nitrogen. Aktifitas mikroba di tanah atau air menguraikan sampah yang mengandung nitrogen organik pertamapertama menjadi ammonia, kemudian dioksidasikan menjadi nitrit dan Nitrat $\left(\mathrm{NO}^{3-}\right)$. Oleh karena nitrit dapat dengan mudah dioksidasikan menjadi Nitrat $\left(\mathrm{NO}^{3-}\right)$, maka Nitrat $\left(\mathrm{NO}^{3-}\right)$ adalah senyawa yang paling sering ditemukan di dalam air bawah tanah maupun air yang terdapat di permukaan. Senyawa nitrogen dalam jumlah yang kecil tidak menimbulkan gangguan, sebaliknya dalam kadar yang tinggi dapat menyebabkan kesakitan bahkan kematian. Selain itu juga dapat menyebabkan methoemoglobinaemia pada bayi berusia muda, terutama yang diberi makanan yang dicampur dengan air yang mengandung nitrat/nitrit (terutama bersumber air sumur).

$$
\text { Kenyataan di masyarakat, }
$$

permasalahan kualitas air yang sering dijumpai yang digunakan masyarakat kurang memenuhi syarat sebagai air minum yang sehat. Sumber air minum seringkali tercemar oleh buangan industri yang mengandung nitrat, nitrit dan amonia. Sumber lainnya adalah dari limbah pertanian yang menggunakan pupuk kima secara berlebihan. Oleh karena itu menurut Peraturan Menteri Kesehatan No. 416 Tahun 1990 ditetapkan bahwa kadar nitrat (sebagai notrogen) dan nitrat (sebagai nitrogen) mkasimum dalam air minum yang diperbolehkan adalah masingmasing $10 \mathrm{mg} / \mathrm{L}$ dan $1 \mathrm{mg} / \mathrm{L}$.

Dengan melihat dampak ditimbulkan oleh kadar Nitrat $\left(\mathrm{NO}^{3-}\right)$ pada air sumur gali yang digunakan oleh masyrakat pada kawasan peisisir, maka peluang terjadinya atau risiko keracunan Nitrat $\left(\mathrm{NO}^{3-}\right)$ pada bayi yang terpapar melalui ibu menyusui. Untuk itu upaya dalam mereduksi dan meminimalisir kadar parameter Nitrat $\left(\mathrm{NO}^{3-}\right)$ bagi sumur gali dikawasan pesisir dan kepulauan dapat dilakukan salah satunya melalui metode dengan pertukaran ion (ion exchange).

Berdasarkan survei kesehatan lingkungan yang pernah dilakukan didaerah kawasan pesisir yakni pulau Sappuli yang ada di kabupaten pangkep, didapatkan gambaran dan kondisi masyrakat yang masih menggunakan sumber air bersih dari sumur gali yang ada dipulau tersebut, adapun hasil interview dengan masyrakat sekitar diperoleh informasi bahwa sebagian masyrakat masih menggunakan air sumur gali tersebut sebagi sumber air bersih dalam memenuhi kebutuhan mandi mencuci membilas dan lain sebagainya adapun untuk keperluan penyediaan air minum yang tentunya dengan melalui pemanasan sebelumnya serta untuk digunakan untuk mencuci beras, sayuran dan makanan lainnya.

Aktivitas pemenuhan kebutuhan air bersih dan air minum sehari hari masyarakat yang ada didaerah pesisir tersebut dinilai sangat berpotensi sebagai jalan masuknya (port de entry) kadar Nitrat $\left(\mathrm{NO}^{3-}\right)$ nitrogen kedalam tubuh manusia. Kegiatan pencucian dan pemenuhan air minum jika tidak mendapat upaya pengelohan sebelumnya tentu ekan memeberi dampak berupa kejadiankeracunan (blue baby disease) nitrit utamanya kepada manusia yang rentan dalam hal ini terhadap ibu dan anak bayi.

Sebagai upaya preventif dalam meminimalisir atau menghindari kejadian tersebut maka peneliti mencoba upaya teknologi terapan sebagai alternatif dalam mereduksi kadar Nitrat $\left(\mathrm{NO}^{3-}\right)$ pada air sumur gali yang dikawasan pesisir dalam 
mengurangi risiko terjadi kejadian blue baby disease pada ibu dan anak. Selain itu pengolahannya diharapakan dapat memenuhi baku mutu efluen dan tentunya aman diterima oleh badan air dan ramah lingkungan.

Sebagai upaya untuk menanggulangi masalah tersebut, telah berbagai cara dan teknologi penghilangan yang dapat dibuat, dikembangkan dan diterapkan sesuai dengan kondisi permasalahan yang ada dan sosial budaya masyarakat. Dalam panduan ini akan disajikan beberapa teknologi penghilangan senyawa nitrogen khususnya nitrat, Sedangkan untuk pengembangan keterampilan dalam penelitian ini, maka akan dipilihkan dua teknologi berupa upaya penyediaan sistem alat pengolahan air skala rumah tangga yang dapat menghilangkan atau mengurangi kandungan nitrogen yang terdapat dalam air sumur, air tanah dan air permukaan. Teknologi tersebut adalah pertukaran ion

\section{METODE PENELITIAN}

Penelitian ini merupakan penelitian praeksperimen yang berfungsi untuk mengetahui penurunan kadar Nitrat $\left(\mathrm{NO}^{3-}\right)$ dengan metode ion exchange pada air sumur gali didaerah kawasan pesisir. Penelitian dilakukan di Laboratorium Terapan dan Rekayasa Lingkungan Politeknik Kesehatan Makassar Jurusan Kesehatan Lingkungan. Lokasi pengambilan sampel yaitu pada beberapa air sumur gali yang berada di pulau Sappuli Desa Mattiro Baji Kab. Pangkep

Pengolahan air sumur gali telah dilakukan melauli tahap penampungan pada bak reservoir sehingga selanjutnya pengaliran pada media filter dan media penukar ion selanjutnya selanjutnya dialirkan pada bak penampungan multimedia filter. Adapun pengambilan sampel air sumur gali sebelum pengolahan sebanyak tiga sampel dan setelah perlakuan pengolahan sebanyak tiga sampel selanjutnya dilakukan pemeriksaan di Laboratorium.
Tabel 1. Alat dan Bahan Penelitian

\begin{tabular}{|c|c|c|c|}
\hline No & Alat/Bahan & Unit & Jumlar \\
\hline 1 & Reservoir & Buah & \\
\hline 2 & Tabung filter PVC 6 inch & Batang & \\
\hline 4 & Pipa PVC $1 / 2$ inch & Batang & \\
\hline 5 & Pasir Kuarsa & $\mathrm{Kg}$ & \\
\hline 6 & Media penukar & $\mathrm{Kg}$ & \\
\hline 7 & anion/kation) & $\mathrm{Kg}$ & \\
\hline 8 & Karbon Aktif & Buah & \\
\hline 9 & Filter matt & Buah & \\
\hline 10 & Tabung cartridge + filter & Buah & \\
\hline 11 & Balok penyangga & Buah & \\
\hline 12 & Paku & Buah & \\
\hline 13 & Stop Kran & Buah & \\
\hline & $\begin{array}{l}\text { Sock } 1 / 2 \text { inch (Tee, Elbc } \\
\text { lurus) }\end{array}$ & & \\
\hline
\end{tabular}

Sumber : Data Primer, 2017

Metode proses ini diawali dengan pengambilan air sumur gali kemudian dimasukkan kedalam bak equalisasi selanjutnya dialirkan up flow (arah aliran dari bawah keatas), pada penagliran ini air akan sumur gali akan disaring oleh lapisan kuarsa selanjutnya akan mengalami proses ion exchange (penukar ion) pada lapisan media filter zeolit dengan ketebalan dan pengaliran yang disesuaikan dalam satuan $\mathrm{ml} /$ detik. Selanjutnya air sumur gali tersebut merambat ke lapisan karbon aktif untuk mengalami proses adsorbsi menetralisir kondisi bau rasa dan warna air selanjutnya tahap akhir melalui catridge filter sebagai pengolahan untuk menjernihkan air olahan. Untuk analisa kualitas air olahan maka pengambilan sampel air dilakukan pada tahap sebelum air sumur gali melalui tahap pengolahan dan setelah air sumur gali melalui/melewati tahap pengolahan dengan pemeriksaan sebanyak tiga kali untuk mendapatkan angka rata-rata hasil pemeriksaan. 


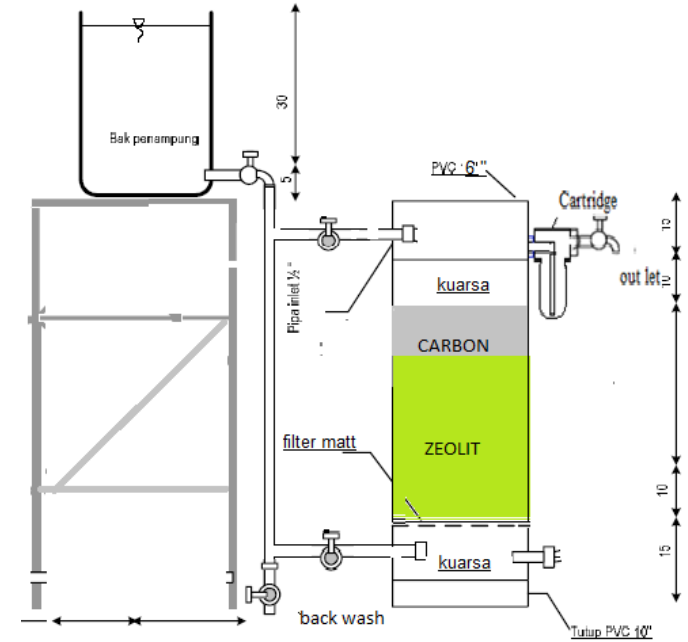

\section{Gambar 1. Desain Pengolahan Air Sumur Gali dengan metode Penukar Ion}

Data hasil penelitian diperoleh dari pengamatan dan pemeriksaan laboratorium sebelum dan setelah pengolahan sebanyak 3 kali (replikasi) selanjutnya dianalisa secara deskriptif yang dilengkapi dengan tabel, grafik dan narasi yang menggambarkan secara menyeluruh dari proses pengolahan dalam mereduksi parameter Nitrat (NO3-). Untuk mengetahui seberapa besar efesiensi penurunan dihitung dengan rumus sebagai berikut :

Penyisihan

$$
=\frac{\overline{\mathrm{X}}_{\text {Sebelum pengolahan }}-\overline{\mathrm{X}}_{\text {Setelah Pengolaha }}}{X \text { Sebelum pengolahan }}
$$

\section{HASIL}

\section{Kalitas Nitrat (NO3-) Air Sumur Gali}

Hasil analisa dan kualitas Air Gumur Gali yang diteliti melalui tahap pemeriksaan awal Air Gumur Gali sebelum dan setelah pengolahan dengan filterasi penukar ion, hasil olahan diperiksa dilaboratorium dengan hasil sebagai berikut :

Tabel 2. Hasil Pemeriksaan Kadar Nitrat (NO3-) Air Sumur Gali

\begin{tabular}{ccccc}
\hline No. & \multicolumn{2}{c}{$\begin{array}{c}\text { Kualitas Nitrat } \\
(\text { NO3-) }\end{array}$} & Penurunan & Persentase \\
\cline { 2 - 5 } & $\begin{array}{c}\text { Sebelum } \\
(\mathrm{mg} / \mathrm{l})\end{array}$ & $\begin{array}{c}\text { Setelah } \\
(\mathrm{mg} / \mathrm{l})\end{array}$ & $(\mathrm{mg} / \mathrm{l})$ & $(\%)$ \\
1. & 16,6 & 5,8 & 10,8 & 65,06 \\
2. & 16,5 & 5,6 & 10,9 & 66,06 \\
3. & 16,2 & 5,6 & 10,6 & 65,43 \\
$\begin{array}{c}\text { Rata- } \\
\text { rata }\end{array}$ & 16,43 & 5,67 & 10,77 & 65,52 \\
\hline Sumber : Data Primer, 2017 &
\end{tabular}

Sumber : Data Primer, 2017
Berdaskan tabel hasil pemeriksaan diatas menunjukkan kadar Nitrat (NO3-) dengan rata rata kadar awal sebesar 16,43 $\mathrm{mg} / \mathrm{l}$ dengan kadar Rata -rata setelah pengolahan sebesar $5,67 \mathrm{mg} / \mathrm{l}$ dengan ratarata penurunan sebesar $10,77 \mathrm{mg} / \mathrm{l}$ atau penurunan dengan persentase sebesar 65, $52 \%$. Kualitas Air Gumur Gali setelah pengolahan telah memenuhi persyaratan, sesuai memenuhi persyaratan air bersih menurut Permenkes No.416/1990 adalah 10 $\mathrm{mg} / \mathrm{L}$. Adapun hasil penurunan dapat dilihat pada gambar berikut.

\section{Gambar 2. Kondisi Penurunan Kadar Nitrat (NO3-) Air Gumur Gali Sebelum dan Setelah Pengolahan Dengan Metode Filterasi Ion Exchange Makassar Tahun 2017}

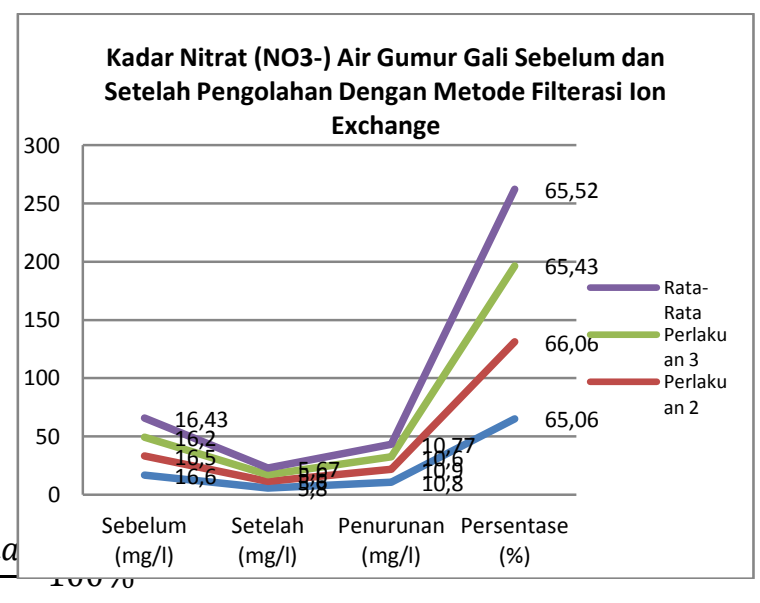

Berdasarkan gambar grafik diatas maka dapat diketahui bahwa metode pengolahan yang digunakan memiliki kemapuan untuk menurunkan kadar Nitrat (NO3-) pada air Air Gumur Gali walaupaun dari segi persyaratan belum memenuhi persyaratan.

\section{PEMBAHASAN}

Penelitian ini dilakukan sabagai salah satu upaya dalam menerapkan teknologi tepat guna bagi masyarakat dan solusi dalam dalam menghadapi permasalahan kesehatan lingkungan khsususnya kondisi pencemaran lingkungan akibat aktivitas manusia terhadap lingkungan. melaui penelitian ini diharapkan menjadi alternatif penerapan teknologi dalam rangka mempertahankan kondisi keseimbangan lingkungan dan ketersedian sekaligus alternatif pemecahan masalah air bersih yang digunakan masyarakat pada daerah kawasan pesisir. dalam rangka mengantisipasi kelangkaan sumber air bersih 
dimasyarakat maka dapat dikatakan capaian atau target yang masih diperlukan untuk mendapat perhatian yang lebih serius. Oleh karena itu upaya tersebut perlu disertai dengan implementasi metode yang telah teruji sehingga memberi hasil yang optimal dan berkelanjutan, ini merupakan visi dan ekpektasi seluruh elemen baik langsung maupun tidak langsung, sehingga akan menjadi paradigma yaitu efesiensi dan efektifisasi sumber daya alam sebagai wujud upaya peningkatan derajat kesehatan.

Upaya penerapan dari sebuah teknologi harus dapat menjawab persoalan dan permasalahan yang dihadapi didasarkan pada ketentuan dan sistem regulasi yang mengatur kesehatan masyarakat khususnya analisa dan standar baku mutu lingkungan yang terkait khususnya pengawasan kulitas air.

Keberadaan kadar Nitrat (NO3-) pada Air Sumur Gali yang Digunakan Masyarakat

Berdasarkan observasi pada lokasi penelitian diketahui kondisi sumur gali dengan karakteristik air yang payau atau agak asin dan sangat dipengaruhi oleh intrusi air laut pada saat terjadinya pasang surut dan musim. Luas lahan yang menjadikan suatu daerah pesisir atau kepulauan memiliki karakteristik dan kondisi yang sangan dipengaruhi oleh air laut.

Kondisi sumur gali masih dikategorikan belum memenuhi syarat yakni cincin sumur yang belum sepenuhnya kedap dan menhana air rembesan, dinding sumur serta lantai sumuryang sebaian besar sudah retak sehinga menjadi faktor kontaminsai dari lingkungan, selain itu jarak sumur gali dengan saluran air limbah dan sampah rumah tangga yang tidak tertangani secara benar, kondisi inilah merupakan faktor terjadi cemaran pada kualitas air sumur gali yang digunakan oleh masyrakat setempat untuk pemenuhan air bersih ataupun kebutuhan air minum yang melalui proses pencucian bahan makanan dan sayuran yang akan dikonsumsi masyarakat.

Kandungan nitrat pada air sumur gali yang diperiksa masih dibawah standar namun dengan adanya kadar nitrat pada sumur gali bisa memberi indikasi adanya cemaran yakni proses perombakan nitrogen oleh mikroorganisme. Nitrat (NO3-) adalah ion-ion anorganik alami, yang merupakan bagian dari siklus nitrogen. Aktivitas mikroba di tanah atau air menguraikan sampah yang mengandung nitrogen organik pertama pertama menjadi ammonia, kemudian dioksidasikan menjadi nitrat, maka nitrat adalah senyawa yang palingsering ditemukan didalam air bawah tanah maupun air yang terdapat di permukaan.

Hal ini sangat berbahaya bila kandungan nitrat ini dikonsumsi oleh anak bayi dan dapt menimbulkan keracunan akut. Bayi yang baru berumur beberapa bulan belum mempunyai keseimbangan yang baik antara usus dan bakteri usus. Sebagai akibatnya, nitrat yang masuk dalam saluran pencernaan akan langsung diubah menjadi nitrit yang kemudian berikatan dengan hemoglobin membentuk methemoglobin yang terbentuk dalam tubuh mereka akan mengakibatkan timbulnya sianosis pada bayi. Nitrat yang deikonsumsi oleh bayi di bawa umur 3 bulan akan beruba menjadi nitrat yang berbahaya, karena nitrat akan menghambat darah melepaskan oksigen ke sel - sel tubuh. Sekali nitrat masuk kedalam sistim peredaran darah, penderita dapat mengalami kekurangan oksigen dalam tubuhnya. Penyakit ini dikenal sebagai methemoglobinemia atau "baby blue Syndrome"yang dapat menjadi penyebab kematian bagi bayi dibawah umur 3 bulan.

Konsomsi air yang mengandung nitrat tinggi oleh wanita hamil dan ibu yang menyusui tidak seperti bila bayi itu mengkonsumsi langsung. Pada kasus ini tidak terlalu jelas, untuk itu hanya direkomendasikan untuk wanita yang mengandung dan yang sementara menyusui agar dapat mengurangi kemungkinan mengkonsumsi air yang mengandung nitrat (Henni Ompusunggu, 2009)

\section{Kemampuan Metode Filterasi Ion Exchange dalam Menurunkan Kadar Nitrat (NO3-) pada Air Sumur Gali}

Terjadinya penurunan kadar nitrat (No3-) pada air sumur gali yang telah melalui tahap pengolahan awalyang terdiri dari media pasir yang berfungsi sebagai pemisah dari pertikel-partikel padat dan penyebab kekeruhan selanjutnya air tersebut menaglir secara up flow ke media filter zeolit kation yang berfungsi sebagai penukar ion (ion exchange) Air Gumur Gali dengan karakteristik ion bermuatan negatif (anion) zeolit yang merupakan adsorben. Zeolit mempunyai struktur pori yang sangat terbuka dan mempunyai luas permukaan internal yang luas sehingga mampu mengadsorpsi sejumlah besar partikel selain air. Penurunan kadar nitrat (No3-) ini disebabkan dengan semakin tinggi bahan isian yang digunakan menyebabkan $\mathrm{pH}$ air sumur gali yang diolah 
ke arah netral, karena sifat zeolit yang mirip kapur. Pada suatu titik tertentu penyisihan nitrat (No3-) tidak terlalu signifikan. Hal ini disebabkan karena zeolit yang digunakan sudah mengalami kejenuhan, penambahan ketinggian menyebabkan volume zeolit semakin besar, penambahan volume ini ternyata menyebabkan terjadinya penggumpalan adsorben sehingga permukaan adsorben tidak seluruhnya terbuka. Hal ini menyebabkan berkurangnya luas permukaan aktif dari adsorben sehingga proses penjerapan (Afrianita dkk, 2010). Dalam proses adsorpsi, ukuran partikel dan kontaminan sangat berpengaruh terhadap kemampuan penyisihan (Watson dalam Reri Afrianita, dkk 2010). Hal ini yang mengurangi kapasitas penyerapan nitrat (No3-). Selain itu, Watson juga memaparkan bahwa slektifitas media penjerap dalam menyisihkan polutan akan menurun jika terdapat banyak komponen yang ingin disisihkan. Salah satu karakter zeolit adalah dari pembentukan kerangka struktur molekular dari penggabungan molekul - molekul tetrahedral membentuk celah - celah dan saluran yang teratur sehingga menyebabkan adanya struktur berpori yang memungkinkan suatu molekul dapat melewati atau terperangkap dalam struktur kristal.

Terjadinya penyisihan parameter dikarenakan ion nitrat (No3-) pada air sumur gali melewati atau terperangkap pada struktur kristal pada zeolit sehingga memungkinkan terjadinya penukaran ion secara merata sebelum air olahan dengan pengalir sistem down flow ke media carbon aktif yang berfungsi sebagai adsorben dan meyerap kadar organik yang dapat menyabkan gangguan bau, rasa dan warna pada air olahan.

Proses penyaringan pada lapisan media karbon aktif adalah proses adsorpsi yang merupakan pengumpulan dari bahanbahan pada permukaan di antara 2 fasa. Kebanyakan bahan yang dilarutkan dalam cairan akan berakumulasi, dan proses adsorpsi mengambil manfaat dari peristiwa ini untuk menghilangkan bahan dari fasa cairan. Sejumlah adsorben (bahan penyerap) digunakan dalam industri, namun hanya satusatunya, karbon aktif, yang mempunyai dua keuntungan yaitu selain murah harganya juga bersifat adsorben nonpolar. Sedangkan adsorben polar bersifat menarik air dan karenanya tidak terlalu bermanfaat.

Proses akumulasi pada permukaan bahan padat yang merupakan lapisan molekul-molekul dari bahan yang terlarut dapat berlangsung oleh karena adanya gayagaya pada permukaan bahan padat yang tidak seimbang.

Proses filtrasi dilakukan dengan memompakan air baku ke bak penampung yang selanjutnya dialirkan ke filter karbon aktif untuk menghilangkan kandungan zat amonium dan bahan mengandung nitrogen lainnya. Kemudian airnya dialirkan ke filter catridge untuk menghilangkan padatan terlarut berukuran $>5$ mikron. Air yang keluar dari catridge ini sudah jernih. Setelah saringan karbon aktif mencapai kapasitas optimalnya, maka harus dilakukan pencucian (backwashing) artinya selama proses berlangsung kemampuan adsorpsi karbon aktif tersebut semakin lama makin berkurang dan akhirnya menjadi jenuh sehingga harus diganti dengan karbon aktif yang baru lama pakai karbon aktif tersebut tergantung kepada kualitas air baku dan jumlah air yang akan disaring. Dalam keadaan normal, penggantian biasanya satu-dua kali dalam setahun.

Sebagai tahap akhir dari pengolahan ini adalah penggunaan filter cartridge yang berfungsi untuk meningkatkan kejernihan atau mengurangi kadar kekeruhan dan padatan pada air olahan, sehingga dari hasil olahan Air Gumur Gali didapatkan kulitas fisik air yakni bau, rasa dan warna yang lebih baik dibandingkan tanpa perlakuan ini.

Melalaui metode perlakuan filterasi dengan media penukar ion (ion exchange)kadar nitrat air sumur gali mengalami penurunan sebesar $10,77 \mathrm{mg} / \mathrm{l}$ dengan persentase kemampuan sebesar $(65,52 \%)$.Metode filterasi penukar ion memiliki kemampuan dalam menurunkan konsentrasi nitrat (No3-) pada air sumur gali. Hal ini dapat menjadi upaya dalam pencegahan konsumsi air sumur gali dengan konsentrasi nitrat (No3) yang tinggi yang dapat mengakibatkan nitrat (No3-) methemoglobinemia pada bayi dan akan memberi pengaruh negatif tersebut adalah penghambatan transport oksigen dalam darah, dalam jumlah besar dapat menyebabkan gangguan diare campur darah, disusul oleh konvulsi, koma, dan bila tidak tertolong akan meninggal. Keracunan kronis dapat menyebabkan depresi, sakit kepala.

Bakteri pereduksi nitrat dalam usus manusia atau hewan akan mengubah nitrat menjadi nitrit. Nitrit tersebut akan mengoksidasi hemoglobin pada darah menjadi methenoglobin yang tidak dapat mengikat oksigen. Walaupun nitrit penyebab masalah pada tubuh manusia, namun karena 
Jurnal Sulolipu : Media Komunikasi Sivitas Akademika dan Masyarakat

Vol. 19 No. 12019

e-issn : 2622-6960, p-issn : 0854-624X

sangat jarang dijumpai dalam makanan dan air maka standar didasarkan pada nitrat yang dapat dijumpai pada makanan, air seperti halnya pada sayuran daun dan bayam (Henni Ompusunggu, 2009)

Methemoglobin adalah hemoglobin yang di dalamnya ion $\mathrm{Fe}$ diubah menjadi ion Fe dan kemampuannya untuk mengangkut oksigen telah berkurang dan menyebabkan darah menjadi coklat. Methemoglobin dapat terjadi apabila hemoglobin terpapar oksidator termasuk nitrat. Sebenarnya darah manusia secara normal mengandung methemoglobin pada konsentrasi tidak lebih dari $2 \%$ tetapi jika methemoglobin meningkat sampai menjadi 10\%-20\% akan mengakibatkan kemampuan darah untuk mengangkut oksigen menjadi sangat terganggu. Darah mengandung methemoglobin yang tinggi disebut methemoglobinemia dengan gejala tubuh berwarna biru (sianosis), sesak nafas, mual dan muntah-muntah dan shock. Kematian dapat terjadi kalau kadar methemoglobin mencapai 70\%. (Silalahi dalam Henni, 2009).

\section{KESIMPULAN}

Sebagaimana tujuan dari penelitian ini yakni Untuk mengetahui kemampuan media filter ion exchange menurunkan kadar nitrat (No3-) pada air sumur gali maka dapat ditarik kesimpulan penelitian sebagai berikut ;

1. Kadar Nitrat (NO3-) awal rata-rata air sumur gali adalah 16,43 mg/l.

2. Media filter ion exchange mampu menurunkan kadar nitrat (No3-)air sumur gali menjadi $5,67 \mathrm{mg} / \mathrm{l}$ dengan penurunan sebesar $10,77 \mathrm{mg} / \mathrm{l}(65,52 \%)$.

\section{DAFTAR PUSTAKA}

Anwar Hadi, (2005) Prinsip Pengelolaan Pengambilan Sampel Lingkungan , PT Gramedia Pustaka Utama,Jakarta.

Budijono, Hasbi, M., \& Ahmali. (2013). Efektivitas Pemakaian Zeolit Sebagai Media Biofilter dalam Menurunkan Polutan Organik Limbah Cair Tahu. University OfRiau.

Chrisafitri, A., \& Karnaningroem, N. (2012). Pengolahan air limbah pencucian mobil dengan reaktor saringan pasir lambat dan karbon aktif. Institut Teknologi Sepuluh Nopember.

Hadari Nawawi \&Mimi Martini, (2005). Penelitian Terapan. Gadjah Mada University Press.

Henni Ompusunggu (2009) : Analisa Kandungan Nitrat Air Sumur Gali Masyarakat Di Sekitar Tempat Pembuangan Akhir (TPA) Sampah Di Desa Namo Bintang Kecamatan Pancur Batu Kabupaten Deli Serdang .

Adenira Hargianintya (2011). Pengolahan Limbah Cair Pencucian Mobil Menggunakan Membran, T., Berpori.

Metcalf and Eddy, Water Engineering Treatment, Disposal,Reuse, 3 nd Edition, McGrawHilllnternational,Singapore, 1991

Nahattands, L. V. (2001). PP No. 82 Tahun 2001 Tentang Pengelolaan kualitas Air dan Pengendalian Pencemaran Air. Republik Indonesia: Deputi Sekretaris Kabinet Bidang Hukum dan Perundang-Undangan.

Peraturan Menteri Kesehatan No. 416 Tahun 1990

(Pusdiklat Pegawai Departemen Keseatan RI, 1986).

Said, N. I., \& Ruliasih. (2005). Tinjauan Aspek Teknis Pemilihan Media Biofilter Untuk Kelompok Teknologi Pengelolaan Air Bersih Dan Limbah Cair, Pusat Pengkajian Dan Penerapan Teknologi Lingkungan, BPPT. Abstract There, 1(3). 